\title{
Relationship between obesity and antipsychotic drug use in the adult population:A longitudinal, retrospective claim database study in Primary Care settings
}

\author{
Antoni Sicras-Mainar' \\ Ruth Navarro-Artieda ${ }^{2}$ \\ Javier Rejas-Gutiérrez ${ }^{3}$ \\ Milagrosa Blanca-Tamayo ${ }^{4}$ \\ 'Planning Management, Badalona \\ Serveis Assistencials S.A., Badalona, \\ Barcelona, Spain; ${ }^{2}$ Medical \\ Documentation Service, Hospital \\ Germans Trías i Pujol, Badalona, \\ Barcelona, Spain; ${ }^{3} \mathrm{Health}$ Outcomes \\ Research Derpartment, Medical Unit, \\ Pfizer Spain, Alcobendas, Madrid, \\ Spain; ${ }^{4}$ Department of Psychiatry, \\ Badalona Serveis Assistencials S.A., \\ Badalona, Barcelona, Spain
}

Objective: To describe the association between obesity and the use of antipsychotic drugs (APDs) in adult outpatients followed-up on in five Primary Care settings.

Methods: A longitudinal, retrospective design study carried out between July 2004 and June 2005 , in patients who were included in a claim database and for whom an APD treatment had been registered. A body mass index (BMI) $<30 \mathrm{~kg} / \mathrm{m}^{2}$ was defined as obesity. The main measurements were: use of APDs, demographics, medical background and co-morbidities, and clinical parameters. Logistic regression analysis and ANCOVA with Bonferroni adjustment were applied to correct the model.

Results: A total of 42,437 subjects (mean age: 50.8 (18.4) years; women: $54.5 \%$; obesity: $27.3 \%$ [ $95 \%$ confidence intervals (CI), 26.9\%-27.7\%]) were analyzed. A total of $1.3 \%$ of the patients were receiving APDs, without statistical differences in distribution by type of drug (typical: $48.8 \%$; atypical: 51.2\%). Obesity was associated with the use of APDs [OR $=1.5$ (CI: 1.3-1.8)], hypertension [OR = 2.4 (CI: 2.2-2.5)], diabetes [OR = 1.4 (CI: 1.3-1.5)] and dyslipidemia [OR $=1.3$ (CI: 1.2-1.4)], $\mathrm{p}<0.0001$ in all cases. BMI was significantly higher in subjects on APDs; 28.8 vs. $27.3 \mathrm{~kg} / \mathrm{m}^{2}, \mathrm{p}=0.002$, and remained higher after adjusting by age and sex (mean difference 0.4 (CI: $0.1-0.7), \mathrm{p}<0.01$ ). After adjusting by age, sex and the Charlson index, obese subjects generated higher average annual total costs than nonobese subjects; 811 (CI: 787-835) vs. 694 (CI: 679-709), respectively, p $<0.001$.

Conclusions: Obesity was associated with the use of APDs, regardless of the type of drug, and with the presence of hypertension, diabetes and dyslipidemia. Obesity was also associated with substantially higher health care costs.

Keywords: Obesity, claim database, retrospective study, antipsychotic use, Primary Care setting, resources utilization, health care costs

\section{Introduction}

Metabolic disorders such as obesity, diabetes or dyslipidemia increase the risk of cardiovascular events (Guallar-Castillón et al 2002). Specifically, obesity exerts an unquestionable impact on population health, due to its high associated morbiditymortality (Guallar-Castillón et al 2002; Mackin et al 2005). Its prevalence in the general population ranges between $6 \%$ and $20 \%$ (The Netherlands, USA), with an increased presence in females and a trend to increase with age, reaching a peak in the decade of 40-50 years. In Spain, the data provided by the Spanish Society for Study of Obesity (SEEDO) (Aranceta-Bartrina et al 2005), and also reported by different studies, indicate percentages in excess of $14 \%$, with a clear tendency to gradually increase in the future (Aranceta-Bartrina et al 2005; Gutiérrez-Fisac et al 2005). 
On the other hand, the use of antipsychotic drugs (APDs) has been increasing considerably during recent years, not only as a result of growth in the population that uses such substances, but also because of expanded use of such medication in other clinical situations in which they are considered to be of potential benefit for patients. However, the evidence to date suggests that antipsychotics, or at least some of the most widely used APDs, are associated with a considerable increase in patient body weight $(>7 \%)$ and with the development of glucose and lipid metabolic alterations. This in turn can imply an increased risk of premature death among such patients due to cardiovascular events (Haupt 2006; Tandon et al 2006; Wu et al 2006). These repercussions are more notorious in the case of second generation APDs (atypical drugs), though the level of risk tends to vary according to the different drug substances used (Babidge et al 2001; Morgan et al 2003; Hiroeh et al 2001). These drugs increase the activity of AMP kinase within the hypothalamus, blocking the activity of the $\mathrm{H}_{1}$ histamine receptors. In this way, a link is established between weight gain and atypical APD use. Although the typical or classical APDs also induce this side effect, the precise mechanism involved in this case is not known (Haupt 2006). Nevertheless, considerable controversy is found among different authors. As an example, clozapine and olanzapine, in addition to the known increases in body weight, can also elevate cholesterol and triglyceride concentrations (ADA et al 2004; Kane et al 2004; Fenton et al 2006; Pujol-Domenech et al 2006), or increase the risk of developing diabetes mellitus (Aranceta-Bartrina et al 2005; Flores-Meneses et al 2005). Similar results have also been recorded in patients treated with risperidone, though the negative effects upon the health of these subjects are somewhat more controversial. Unfortunately, the role and importance of each of them are often difficult to assess, and it is likewise difficult to determine whether certain biological alterations are the cause or effect of the excess body weight (Jin et al 2004; Dinca et al 2005; Flores-Meneses et al 2005; Haupt 2006; Pujol-Domenech et al 2006; Schneider et al 2006; Woodward et al 2007).

The present study further evaluates previously observed associations between obesity and typical and atypical APD use, and explores its influence upon health care resource utilization in adult outpatients followed-up on by five primary care teams in the Spanish population setting.

\section{Methods}

A retrospective, multicenter study was conducted based on the medical records of adult patients monitored on an outpatient basis and under normal clinical practice conditions. The study population was seen by five Primary Care teams managed by Badalona Serveis Assistencials, S.A., and involving a designated recruitment population of about 105,300 inhabitants ( $14.5 \%$ over 64 years of age). The designated population is predominantly urban, with middle to low socioeconomic level, and working mainly in the industrial setting. Primary care team organization is of a reformed character, involving public management and the provision of private services (concerted). Badalona Serveis Assistencials S.A. possesses personnel, a training policy, organization model and services offered profile similar to that of most primary care centers in Catalonia, Spain, with decentralized management and single structural services.

The study included all patients seen between July 1, 2004 and June 30, 2005, meeting the following criteria: a) age over 18 years; b) initiation of pharmacological treatment with APDs; and c) inclusion in the chronic prescriptions program with regular patient reports for the programmed visits to obtain the corresponding medical prescriptions (with registry of the daily dose, time interval and duration of each treatment). Patients failing to report to the centers were excluded, as were those displaced or outside the zone, and those presenting disabling mental disorders. Obesity was defined as the presence of excess body weight secondary to the accumulation of adipose tissue, with a body mass index (BMI, $\mathrm{kg} / \mathrm{m}^{2}$ ) of over 30 (NCEP 2002). Information was collected on the prescription of APDs (atypical: amisulpiride, clozapine, olanzapine, quetiapine, risperidone and ziprasidone; typical: chlorpromazine, clotiapine, fluphenazine, haloperidol, levomepromazine, perphenazine, periciazine, pimozide, pipothiazine, tiapride, thioproperazine, thioridazine, zuclopentixol), reflected in the computer-based case histories, according to the recommendations of the prescribing physician (WHO 1995). Quantification was made of the number of health problems attended per patient/year (comorbidity), considered as a diagnosis-equivalent disease care problem (International Classification of Primary Care, ICPC) (Lamberts et al 1993). The personal antecedents were the following: arterial hypertension (K86), dyslipidemia (T93), diabetes mellitus (T90), active smoking (P17), alcoholism (P15), ischemic heart disease (K74, cardiac ischemia with angina; K75, acute myocardial infarction; K76, coronary ischemia), cerebrovascular accident (K90, K91), cardiovascular event, chronic obstructive pulmonary disease (R95, chronic airflow obstruction) and bronchial asthma (R96). The Charlson Index was quantified as an estimation of morbidity burden (severity), and the following clinical 
parameters were documented (medical records): systolic blood pressure (SBP, $\mathrm{mmHg}$ ) and diastolic blood pressure (DBP, $\mathrm{mmHg}$ ), baseline blood glucose ( $\mathrm{mg} / \mathrm{dl})$, triglycerides $(\mathrm{mg} / \mathrm{dl})$, total cholesterol $(\mathrm{mg} / \mathrm{dl})$, low density lipoprotein cholesterol (LDL-c, Friedewald in $\mathrm{mg} / \mathrm{dl}$ ) and high density lipoprotein cholesterol (HDLc) in $\mathrm{mg} / \mathrm{dl}$.

The consumed health care resources, documented from the registries of each center, comprised the visits or appointments with the Primary Care center, referrals to the reference specialists, requests for supporting complementary tests, and drug prescriptions charged to CatSalut occurring during the study period of evaluation. Visits made were defined as appointments programmed between the professional team and the patient due to a health demand or problem, in the center or in the home of the patient. The design of the costs system was defined taking into account the characteristics of the organization and the degree of development of the available information systems. The unit health care product serving as basis for final calculation was the cost/patient attended during the study period. According to dependence on the volume of activity carried out, consideration was made of the fixed/semi-fixed costs (with imputation criteria) and the variable costs. Fixed/semi-fixed costs (structure) were taken to be those relating to personnel (fees and salaries), consumer goods, and a series of expenses pertaining to external services, in accordance with the General Accounting Plan for Health Care Centers, while variable costs were taken to be those related to diagnostic or therapeutic requests, or referrals decided by the professionals of the center. The different study concepts and their economical assessment were the following: a) complementary tests, including laboratory tests (mean cost per request), conventional radiology (fee per requested test), and supporting tests (fee per requested test); b) referrals to reference specialists or to hospital centers on an ordinary or emergency basis (adjusted fee per referral); and c) prescriptions (medical prescriptions on an acute or chronic basis, or upon demand; public sales price per container). The fees used were obtained from analytical accountancy studies made within the organization itself, or from prices as established by CatSalut (Garcia-Cardona et al 1995; Orden de la Generalitat de Catalunya 1995). Based on the semi-fixed costs, a mean cost per visit made was obtained, and a final direct distribution was carried out for each patient attended during the study period. Thus, the cost per patient $(\mathrm{Cp})$ was: $\mathrm{Cp}=($ mean cost per visit $x$ number of visits [semi-fixed costs]) + variable costs. As a step prior to analysis, and in particular to the information source pertaining to the case histories retrospective claim database (OMIAP), a careful review was made of the data, in search of possible registry or coding errors. Data quality was considered adequate, and the data were obtained on a computerized basis, with due observation of the legal regulations on information confidentiality.

A statistical analysis was made, with calculation of the mean and standard deviation (SD), and corresponding 95\% confidence intervals (CI). Parametric tests (chi-square and Student t-test) were used for the relationship between variables in the bivariate analysis. A logistic regression analysis (forward step procedure) was performed to correct the model, including the variables according to significance of the results in the bivariate analysis and their clinical significance (dependent variable: obesity). Comparison of ambulatory cost was made following the recommendations of Thompson and Barber (2000) based on analysis of covariance (ANCOVA) with patient sex, age, and number of co-morbidities as covariates (estimation of marginal means; Bonferroni correction). The SPSSWIN version 12 statistical package was used, accepting statistical significance for $\mathrm{p}<0.05$.

\section{Results}

Information was obtained on 42,437 patients (Table 1 ), with a mean age of 50.8 (18.4) years (54.5\% females). The mean number of visits/year was 10.0 (9.0), with a mean number of episodes/year of 5.9 (3.8), and a mean Charlson Index of 0.4 (0.6). According to the NCEP-ATP III, 27.3\% (95\% CI: $26.9 \%-27.7 \%$ ) of the population attended met criteria of obesity $\left(\mathrm{BMI}=27.4 \mathrm{~kg} / \mathrm{m}^{2}\right)$, while $1.3 \%$ (CI: 1.2\%-1.4\%) were receiving treatment with APDs - fundamentally olanzapine $(23.3 \%)$, risperidone $(22.1 \%)$ and haloperidol $(11.3 \%)$. The main reason for using antipsychotics were disorders of the schizophrenia spectrum [254 (46.1\%)], bipolar disorders [95 (17.3\%)], dementia and other cognitive deficits [71 (12.8\%)], restlessness [41 (7.5\%)], anxiety [25 (4.5\%)], organic psychoses [24 (4.4\%)], and others [41 (7.4\%)].

The proportion of individuals receiving treatment with APDs was significantly greater among the obese patients: $1.8 \%$ vs. $1.1 \%, \mathrm{p}<0.0001$, though there were no differences in proportion between conventional and atypical drugs: $48.8 \%$ vs. $51.2 \%$, respectively, or in terms of the drug substance involved (Table 1). Obesity was associated with the majority of the general variables, co-morbidities and clinical parameters studied. A greater mean age of 57.9 (15.5) years vs. 48.2 (18.8) years, with a predominance of females $59.9 \%$ vs. $52.4 \%$, and a greater number of visits $12.1(9.8)$ vs. 9.1 (8.5) and episodes 7.0 (4.0) vs. 5.4 (3.6), respectively $(p<0.001)$ was seen in all cases. In these patients, a larger proportion of modifiable cardiovascular risk antecedents 
Table I General characteristics of the study sample in the absence or presence of obesity

\begin{tabular}{|c|c|c|c|c|}
\hline Study variables & Nonobese $(n=30,843)$ & Obese $(n=11,594)$ & Total $(n=42,437)$ & $\mathbf{P}$ \\
\hline Subjects treated with APDs (\%) & $\mathrm{n}=344(1.1 \%)$ & $\mathrm{n}=207(\mathrm{I} .8 \%)$ & $\mathrm{n}=55 \mathrm{I}(\mathrm{I} .3 \%)$ & $<0.000 \mathrm{I}$ \\
\hline \multicolumn{5}{|l|}{ General } \\
\hline Mean age (SD), years & $48.2(18.8)$ & $57.9(\mid 5.5)$ & $50.8(18.4)$ & $<0.0001$ \\
\hline Sex (females) & 52.4 & 59.9 & 54.5 & $<0.0001$ \\
\hline Mean visits/year & $9.1(8.5)$ & I2.I (9.8) & $10.0(9.0)$ & $<0.0001$ \\
\hline Body mass index $(\mathrm{SD}), \mathrm{kg} / \mathrm{m}^{2}$ & $25.0(3.0)$ & $33.8(3.6)$ & $27.4(5.1)$ & $<0.0001$ \\
\hline Mean episodes/year & $5.4(3.6)$ & $7.0(4.0)$ & $5.9(3.8)$ & $<0.0001$ \\
\hline Mean Charlson Index & $0.3(0.6)$ & $0.5(0.7)$ & $0.4(0.6)$ & $<0.0001$ \\
\hline \multicolumn{5}{|c|}{ Antecedents or associated comorbidities } \\
\hline Arterial hypertension & 19.9 & 47.0 & 27.3 & $<0.0001$ \\
\hline Dyslipidemia & 22.6 & 35.9 & 26.3 & $<0.0001$ \\
\hline Diabetes mellitus & 9.0 & 19.0 & 11.7 & $<0.0001$ \\
\hline Smokers & 29.2 & 18.5 & 26.3 & $<0.000$ I \\
\hline Ischemic heart disease & 3.5 & 6.2 & 4.3 & $<0.0001$ \\
\hline Stroke & 2.0 & 2.3 & 2.1 & 0.042 \\
\hline Cardiovascular events & 6.3 & 9.2 & 7.1 & $<0.0001$ \\
\hline Alcoholism & 1.9 & 1.7 & 1.8 & NS \\
\hline Chronic obstructive pulmonary disease & 2.9 & 4.5 & 3.4 & $<0.0001$ \\
\hline Bronchial asthma & 3.8 & 4.7 & 4.1 & $<0.0001$ \\
\hline \multicolumn{5}{|l|}{ Clinical parameters } \\
\hline Systolic blood pressure (SD), $\mathrm{mmHg}$ & $127.0(\mid 6.6)$ & I35.2(|6.1) & $129.6(16.9)$ & $<0.0001$ \\
\hline Diastolic blood pressure (SD), $\mathrm{mmHg}$ & $75.1(9.5)$ & $79.5(9.4)$ & $76.5(9.7)$ & $<0.0001$ \\
\hline Baseline blood glucose (SD), mg/dl & $95.1(25.5)$ & $106.6(32.8)$ & $98.5(28.4)$ & $<0.0001$ \\
\hline Serum triglycerides (SD), mg/dl & II $2.3(75.2)$ & $140.6(89.7)$ & $121.5(81.3)$ & $<0.0001$ \\
\hline Total cholesterol (SD), mg/dl & $204.9(45.3)$ & $221.4(42.3)$ & $217.7(43.6)$ & $<0.0001$ \\
\hline HDL-cholesterol (SD), mg/dl & $48.3(13.7)$ & $44.0(12.0)$ & $46.9(13.3)$ & $<0.0001$ \\
\hline LDL-cholesterol (SD), mg/dl & I38.0 (36.1) & I43.I (34.3) & $139.6(35.6)$ & $<0.0001$ \\
\hline
\end{tabular}

Notes: Values are given as percentage or mean.

Abbreviations: SD, standard deviation; p, statistical significance; NS, nonsignificant; APD, antipsychotic drug; HDL-cholesterol, high density lipoprotein cholesterol; LDLcholesterol, low density lipoprotein cholesterol.

was observed: arterial hypertension $47.0 \%$ vs. $19.9 \%$, dyslipidemia $35.9 \%$ vs. $22.6 \%$, diabetes mellitus $19.0 \%$ vs. $9.0 \%$; and cardiovascular events $9.2 \%$ vs. $6.3 \%$, respectively, $\mathrm{p}<0.001$. The clinical parameters, systolic blood pressure: 135.2 (16.1) vs. 127.0 (16.6) mmHg; triglycerides: 140.6 (89.7) vs. 112.3 (75.2) mg/dl; total cholesterol: 221.4 (42.3) vs. 204.9 (45.3) $\mathrm{mg} / \mathrm{dl}$, and baseline blood glucose: 106.6 (32.8) vs. $95.1(25.5) \mathrm{mg} / \mathrm{dl}$, respectively $(\mathrm{p}=0.001)$, in all cases (Table 1). BMI was significantly higher in subjects on APDs: 28.8 vs. $27.3 \mathrm{~kg} / \mathrm{m}^{2}, \mathrm{p}=0.002$, and remained higher after adjusting by age and sex: mean difference of 0.4 (0.1-0.7, p < 0.01).

In the final logistic model (Table 2), corrected for age and sex, obesity was seen to be associated with APD use
$(\mathrm{OR}=1.5$ [CI: 1.3-1.8]), hypertension $(\mathrm{OR}=2.4[\mathrm{CI}:$ 2.2-2.5]), diabetes (OR $=1.4$ [CI: 1.3-1.5]) and dyslipidemia $(\mathrm{OR}=1.3$ [CI: 1.2-1.4]), $\mathrm{p}<0.001$. Patient age and sex were likewise significantly associated to the presence of obesity; the male sex was associated with a $20 \%-30 \%$ lesser probability of being obese $(\mathrm{p}<0.0001)$, while a one-year increase in age was associated to a $10 \%-30 \%$ increase in the risk of obesity $(\mathrm{p}<0.0001)$. The general characteristics and clinical parameters of the patients according to APD use versus the control group are reported in Table 3 . These subjects show a greater mean age of 56.4 (19.5) vs. 50.7 (18.4) years, BMI $28.8(5.7)$ vs. $27.3(5.1) \mathrm{kg} / \mathrm{m}^{2}$, noticeably higher baseline blood glucose and triglyceride levels, and lower HDLc concentrations, respectively ( $\mathrm{p}<0.001)$, in all cases. 
Table 2 Results of the logistic regression model with obesity as dependent variable

\begin{tabular}{lllll}
\hline Variables of the model & Beta & $\mathbf{p}$ & OR & $\mathbf{9 5 \%} \mathbf{C l}$ \\
\hline Antipsychotics use & $0.42 \mathrm{I}$ & $<0.000 \mathrm{I}$ & $\mathrm{I} .5$ & $\mathrm{I} .3-\mathrm{I} .8$ \\
Age (years) & 0.132 & $<0.000 \mathrm{I}$ & $\mathrm{I} .2$ & $\mathrm{I} . \mathrm{I}-\mathrm{I} .3$ \\
Sex (male) & -0.272 & $<0.000 \mathrm{I}$ & 0.8 & $0.7-0.8$ \\
Arterial hypertension & 0.864 & $<0.000 \mathrm{I}$ & 2.4 & $2.2-2.5$ \\
Diabetes mellitus & 0.323 & $<0.000 \mathrm{I}$ & $\mathrm{I} .4$ & $\mathrm{I} .3-\mathrm{I} .5$ \\
Dyslipidemia & 0.272 & $<0.000 \mathrm{I}$ & $\mathrm{I} .3$ & $\mathrm{I} .2-\mathrm{I} .4$ \\
\hline
\end{tabular}

Abbreviations: OR, odds ratio; $\mathrm{Cl}, 95 \%$ confidence interval.

The total direct costs in Primary Care of the attended patients were 27.7 million euros, with a distribution of $27.1 \%$ corresponding to fixed or semi-fixed costs, and the rest to variable costs. In this context, referrals to reference specialists stood out (8.0\%), along with pharmaceutical prescription: $59.4 \%$ (Table 4). This table reports the total costs and the costs by components; uncorrected observed costs and differential costs corrected for morbidity burden, age and sex among the patients with obesity (versus the nonobese control population). The obese individuals were associated with significantly greater corrected total costs of 811 (CI: 787-835) vs. 694 (CI: 679-709), respectively, $\mathrm{p}<0.001$. All the components of the corrected costs were significantly greater in the presence of obesity.

\section{Discussion}

The results of this study show obese patients seen in the Primary Care setting to represent $27.3 \%$ of the total. Compared with the general population, this markedly high percentage can be explained in part by the fact that the attended patients are not representative of the general population, and because young individuals less commonly resort to health care services. Nevertheless, the lack of knowledge of the specific etiology of the disorder and the scant therapeutic resources available, lead to a limited percentage treatment success that is often followed by recovery of the initial body weight. The above suggests that treatment and preventive activities targeting obesity are inefficient in the Primary Care setting. This in turn generates a certain relaxed approach to this risk factor, and a reluctance to dedicate major efforts to solve the problem - in contrast to other disorders which are more amenable to effective medical intervention.

In the logistic model, obesity was associated with the use of APDs and the presence of hypertension, diabetes and dyslipidemia, and with patient age and sex. These results are similar to those reported in the consulted literature
(Aranceta-Bartrina et al 2005; Gutiérrez-Fisac et al 2005; Haupt 2006; Mackin et al 2005; Tandon et al 2006), though the impact of obesity upon health requires the adoption of a preventive approach that can only be achieved through the generalization of educative and preventive activities (Haupt 2006). These data reflect the importance of preventing weight gain in such patients, with adequate treatment in each case, and posterior supervision of the patients that receive APD therapy - particularly among those presenting a high cardiovascular risk or those who are already obese (Haupt 2006; $\mathrm{Wu}$ et al 2006). No differences were observed between the uses of conventional or atypical APDs in relation to obesity. This may be due to patient selection bias, a statistical artifact, or limited statistical power as a result of the small number of patients in each group (Flores-Meneses et al 2005). Likewise, the possibility that a modification in APD treatment regimen may have altered our findings cannot be ruled out.

Table 3 Overall characteristics and clinical parameters of the patients included in the study according to the use of antipsychotic drugs (APDs)

\begin{tabular}{|c|c|c|c|}
\hline General concepts & $\begin{array}{l}\text { No APDs } \\
(n=41,886)\end{array}$ & $\begin{array}{l}\text { APDs } \\
(n=55 I)\end{array}$ & $\mathbf{p}$ \\
\hline \multicolumn{4}{|l|}{ Characteristics } \\
\hline Sex (females) & $54.5 \%$ & $56.4 \%$ & NS \\
\hline Mean age (SD), years & $50.7(18.4)$ & $56.4(19.5)$ & $<0.0001$ \\
\hline $\begin{array}{l}\text { Body Mass Index (SD), } \\
\mathrm{kg} / \mathrm{m}^{2}\end{array}$ & $27.3(5.1)$ & $28.8(5.7)$ & $<0.0001$ \\
\hline Mean visits/year (SD) & $9.8(8.9)$ & | 4.8 ( $\mid \mathrm{I} .3)$ & $<0.0001$ \\
\hline Mean episodes/year (SD) & $5.9(3.8)$ & $7.1(4.3)$ & $<0.0001$ \\
\hline $\begin{array}{l}\text { Mean Charlson Index } \\
\text { (SD) }\end{array}$ & $0.3(0.6)$ & $0.5(0.7)$ & $<0.0001$ \\
\hline \multicolumn{4}{|l|}{ Clinical parameters } \\
\hline $\begin{array}{l}\text { Systolic blood pressure } \\
\text { (SD), } \mathrm{mmHg}\end{array}$ & $129.6(16.9)$ & $128.2(15.8)$ & NS \\
\hline $\begin{array}{l}\text { Diastolic blood pressure } \\
\text { (SD), } \mathrm{mmHg}\end{array}$ & $76.5(9.7)$ & $75.9(9.4)$ & NS \\
\hline $\begin{array}{l}\text { Baseline blood glucose } \\
\text { (SD), mg/dl }\end{array}$ & $98.4(28.3)$ & I02.I (35.0) & 0.006 \\
\hline $\begin{array}{l}\text { Serum triglycerides (SD), } \\
\mathrm{mg} / \mathrm{dl}\end{array}$ & $121.2(8 \mid .1)$ & I39.6 (90.5) & $<0.0001$ \\
\hline $\begin{array}{l}\text { Total cholesterol (SD), } \\
\mathrm{mg} / \mathrm{dl}\end{array}$ & $206.8(41.5)$ & $207.9(42.2)$ & NS \\
\hline $\begin{array}{l}\text { HDL-cholesterol (SD), } \\
\mathrm{mg} / \mathrm{dl}\end{array}$ & $46.9(13.3)$ & $43.6(12.6)$ & $<0.0001$ \\
\hline $\begin{array}{l}\text { LDL-cholesterol (SD), } \\
\mathrm{mg} / \mathrm{dl}\end{array}$ & I39.6 (35.6) & I39.8 (34.5) & NS \\
\hline
\end{tabular}

Notes: values are given as percentage or mean.

Abbreviations: SD, standard deviation; NS, nonsignificant; HDL-cholesterol, high density lipoprotein cholesterol; LDL-cholesterol, low density lipoprotein cholesterol. 
Table 4 General and unit distribution of the model of costs per patient per year (in euros), in the absence or presence of obesity

\begin{tabular}{|c|c|c|c|c|c|c|c|c|}
\hline & & & Nonobese & $(n=30.843)$ & Obese subjects & $(n=11.594)$ & & \\
\hline Concepts & Total costs & & Mean (SD) & $\begin{array}{l}\text { Corrected } \\
\text { model* }\end{array}$ & Mean (SD) & $\begin{array}{l}\text { Corrected } \\
\text { model* }\end{array}$ & $\begin{array}{l}\text { Mean total cost } \\
\text { per patient }\end{array}$ & $\mathbf{p}^{*}$ \\
\hline Total cost in PC & $27,696,430$ & & $638(1.245)$ & 694 [679-709] & 981 (1.467) & 811 [787-835] & $735(1.320)$ & $<0.000$ I \\
\hline Fixed/semifixed cost & $7,511,580$ & $(27 \%)$ & $182(170)$ & $192[190-194]$ & $242(196)$ & 212 [209-2।5] & $199(180)$ & $<0.0001$ \\
\hline Variable cost & $20,184,850$ & $(73 \%)$ & $455(1.182)$ & $502[488-5 \mid 6]$ & 739 (1.395) & 599 [575-622] & $535(1.253)$ & $<0.0001$ \\
\hline Cost of referrals & $2,211,296$ & $(8 \%)$ & $54(76)$ & $56[55-57]$ & $70(86)$ & $64[62-65]$ & $59(79)$ & $<0.000$ I \\
\hline Pharmaceutical cost & $16,460,466$ & (59\%) & $363(673)$ & $407[400-4 \mid 4]$ & $624(807)$ & 497 [485-5।0] & 437 (723) & $<0.0001$ \\
\hline
\end{tabular}

Notes: Values are given as percentage or mean; costs in euros ( ); *adjusted p level; each F-test contrasts the simple effect of obesity in each combination of levels of the rest of effects shown. These contrasts are based on comparisons by pairs (linearly independent), between the estimated marginal means. The co-variables appearing in the model are evaluated in the following values: Charlson Index $=0.35$, mean age $=52.2$. Method: Bonferroni correction.

Abbreviations: SD, standard deviation and $95 \%$ confidence interval; PC, Primary Care.

In studies of the use of psychoactive drugs, and in coincidence with our own observations, a larger proportion of treatments were seen to correspond to women - this possibly being due to the greater tendency among women to visit Primary Care centers (Ustun 1999; Vedia et al 2005). If the behavioral pattern among males is changing, then this discrepancy between the costs of males and females could decrease over time. It therefore would be interesting to conduct similar studies in the future, to confirm this possibility. A relevant observation in our study is that patients show increased health care resource consumption at all levels, regardless of age, sex or morbidity - thus resulting in an increased cost per patient per year. The largest difference in this sense corresponds to pharmacological expenditure. This cost could be due to the greater number of drug substances consumed, though it cannot be ruled out that part of the difference may be attributable to a greater purchasing cost for psychoactive medicines, or to the possibility that patients of this kind are prescribed latest-generation (and more expensive) drugs for the treatment of other mental problems. The second most important cost component corresponded to medical visits in the Primary Care setting. This coincides with the literature, where in general psychiatric patients are seen to seek care more often, and do so more in Primary Care centers than in psychiatric clinics (Kokkinos et al 2005). In this context, in a study of the epidemiology and use of health care resources related to mental health in Primary Care, reported that these patients present higher consulting rates than those individuals without mental disease (Vázquez et al 1997). The highest consulting rates were likewise associated with the demographic variables of patient sex (female) and age.

The results obtained can be explained not only by the different geographical composition of the study sample (a factor clearly associated to patient age), but also by other differences implicated in the studies consulted, and which could be explained in part by different health or dietary habits (Katerndahl 1995; Gómez et al 2005). Particularly as relates to obesity, the question emerges as to what other factors could be playing a relevant role in the fact that metabolic syndrome is more prevalent among these patients. In this context, unhealthy living habits could play an important role. In this sense, the role of diet seems to be confirmed, in view of the observed high prevalence of obesity, dyslipidemia, and hypertriglyceridemia. These observations, attributable to diet, lifestyle, or other conditioning factors, appear to coincide with the tendency of schizophrenic patients to accumulate fat and intraabdominal adipose tissue (Hagg et al 2006).

Regardless of the effect of lifestyle and health-damaging habits, attention should also focus on the role of the APDs used as treatment - some of which have been shown to exert a direct influence upon weight gain and lipid and carbohydrate metabolic disorders (Ryan et al 2002; Barnett et al 2006). Although controversy exists surrounding this, such substances could be making an important contribution to the appearance of metabolic disorders with an increased risk of cardiovascular disease. Other possible causes, such as certain alterations of the hypothalamic-pituitary-adrenal neuroendocrine axis inducing increased blood cortisol levels with genotypic expression in the form of abdominal obesity among patients receiving APDs, or the possible effects upon hippocampal volume, are aspects requiring further study and confirmation as potential cardiovascular risk factors in patients of this kind (McIntyre et al 2001).

Other limitations require caution in generalizing the results, including the inherent observational design of the 
study (data underestimation), the possible variability among professionals in the different centers, the coordination of levels (health care continuum), and the lack of prescribed dose adjustment (Tandon et al 2006). Nevertheless, such reformed centers present a very similar intervention organizational and protocol model - thus ensuring a common and homogeneous health care level. In future, new studies will be needed to confirm the consistency of the results obtained, and to evaluate strategies designed to reduce the cardiovascular risk factors. Likewise, it is important to continue advancing in treatment compliance and the achievement of objectives, in order to ensure more costeffective interventions (Tandon et al 2006).

In conclusion, obesity is an important cardiovascular risk factor significantly associated with the use of APDs in the presence of hypertension, diabetes and dyslipidemia, and with patient age and sex as nonmodifiable factors, leading to an increased consumption of health care resources. In our sample, no differences were recorded between the uses of conventional or atypical APDs, though further research under normal clinical practice conditions will be needed to reinforce the consistency of these results.

\section{Disclosure}

There are no conflicts of interest to report.

\section{References}

[ADA] American Diabetes Association, American Psychiatric Association, American Association of Clinical Endocrinologists, et al. 2004. Consensus development conference on antipsychotic drugs and obesity and diabetes. Diabetes Care, 27:596-601.

Aranceta-Bartrina J, Serra-Majem Ll, Foz-Sala M, et al. 2005. Prevalencia de obesidad en España. Med Clin (Barc), 125:460-6.

Babidge NC, Buhrich N, Butler T. 2001. Mortality among homeless people with schizophrenia in Sydney, Australia: a 10-year follow-up. Acta Psychiatr Scand, 103:105-10.

Barnett M, Argo T, Alexander B, et al. 2006. A regional comparison of developing diabetes among Veterans Affairs patients exposed to typical and atypical antipsychotics relative to corticosteroids and proton pump inhibitors. Ann Clin Psychiatry, 18:1-7.

Dinca O, Paul M, Spencer NJ. 2005. Systematic review of randomized controlled trials of atypical antipsychotics and selective serotonin reuptake inhibitors for behavioural problems associated with pervasive developmental disorders. J Psychopharmacol, 19:521-32.

Fenton WS, Chavez MR. 2006. Medication-induced weight gain and dyslipidemia in patients with schizophrenia. Am J Psychiatry, 163:1697-1704.

Flores-Meneses L, Sanmarti-Sala A. 2005. Atypical antipsychotics: new aetiology in type 2 diabetes mellitus. Med Clin (Barc), 124:341-3.

Garcia-Cardona F, Molins-Perez G, Farre-Pradell J, et al. 1995. Cost accountability in primary care: list of services. Aten Primaria, 16:141-5.

Gómez P, Fernández de la Puebla RA, Castro P, et al. 2005. Effect of the Mediterranean diet on fasting concentrations of activated factor VII in healthy persons. Rev Esp Cardiol, 58:285-9.
Guallar-Castillón P, Banegas-Banegas JR, García-Yébenes MJ. 2002. Asociación de la enfermedad cardiovascular con el sobrepeso y la obesidad en España. Med Clin (Barc), 118:616-18.

Gutiérrez-Fisac JL, Regidor E, Rodríguez-Artalejo F. 2005. Prevalencia de obesidad en la población adulta española: 14 años de incremento continuado. Med Clin (Barc), 124:196-7.

Hagg S, Lindblom Y, Mjorndal T, et al. 2006. High prevelence of the metabolic syndrome among a Swedish cohort of patients with schizophrenia. Int Clin Psychopharmacol, 21:93-8.

Haupt DW. 2006. Differential metabolic effects of antipsychotic treatments Eur Neuropsychopharmacol, 16(Suppl)3:S149-55.

Hiroeh U, Appleby L, Mortensen PB, et al. 2001. Death by homicide, suicide, and other unnatural causes in people with mental illness: a populationbased study. Lancet, 358:2110-12.

Jin H, Meyer JM, Jeste DV. 2004. Atypical antipsychotics and glucose dysregulation: a systematic review. Schizophr Res, 71:195-212.

Kane JM, Barret EJ, Casey DE, et al. 2004. Metabolic effects of treatment with atypical antipsychotics. $J$ Clin Psychiatry, 65:1447-55.

Katerndahl DA. 1995. Problemas conductuales y psiquiátricos. In: Taylor RB ed. Medicina de familia, principios y práctica. $5^{a}$ ed. New York: Springer, pp. 289-331.

Kokkinos P, Panagiotakos DB, Polychronopoulos E. 2005. Dietary influences on blood pressure: the effect of the Mediterranean diet on the prevalence of hypertension. J Clin Hypertens (Greenwich), 7:165-70.

Lamberts H, Wood M, Hofmans-Okkes IM. 1993. The International Classification of Primary Care in the European Community. With a multi-language layer. Oxford: Oxford University Press.

Mackin P, Watkinson HM, Young AH. 2005. Prevalence of obesity, glucose homeostasis disorders and metabolic syndrome in psychiatric patients taking typical or atypical antipsychotic drugs: a cross-sectional study. Diabetologia, 48:215-21.

McIntyre RS, McCann SM, Kennedy SH. 2001. Antipsychotic metabolic effects: weight gain, diabetes mellitus, and lipid abnormalities. Can J Psychiatry, 46:273-81.

Morgan MG, Scully PJ, Youssef HA, et al. 2003. Prospective analysis of premature mortality in schizophrenia in relation to health service engagement: a 7.5-year study within an epidemiologically complete, homogeneous population in rural Ireland. Psychiatry Res, 117:127-35.

[NCEP] National Cholesterol Education Program - Expert Panel on Detection, Evaluation, and Treatment on High Blood Cholesterol in Adults (Adult Treatment Panel III). 2002. Third report of the National Cholesterol Education Program (NCEP) Expert Panel on Detection, Evaluation, and Treatment of High Blood Cholesterol in Adults. Adult Treatment Panel III final report. Circulation, 106:3143-421.

Orden de la Generalitat de Catalunya de 22 de diciembre de 1995. Diari Oficial de la Generalitat de Catalunya. 2148:9689-90.

Pujol-Domenech J, de-Azpiazu-Artigas P. 2006. Antipsychotics in the elderly: typical or atypical. Med Clin (Barc), 126:415-17.

Ryan MC, Thakore JH. 2002. Physical consequences of schizophrenia and its treatment: the metabolic syndrome. Life Sci, 71:239-57.

Schneider LS, Dagerman K, Insel PS. 2006. Efficacy and adverse effects of atypical antipsychotics for dementia: meta-analysis of randomized, placebo-controlled trials. Am J Geriatr Psychiatry, 14:191-210.

Tandon R, Nasrallah HA. 2006. Subjecting meta-analyses to closer scrutiny: Little support for differential efficacy among second-generation antipsychotics at equivalent doses. Arch Gen Psychiatry, 63:935-7.

Thompson SG, Barber JA. 2000. How should cost data in pragmatic randomised trials be analysed? $B M J, 320: 1197-200$.

Ustun TB. 1999. The global burden of mental disorders. Am J Public Health, 89:1315-18.

Vázquez JL, García J, Simón JA, et al. 1997. Mental health in primary care. An epidemiological study of morbidity and use of health resources. $\mathrm{Br}$ J Psychiatry, 170:529-35.

Vedia C, Bonet S, Forcada C, et al. 2005. Estudio de utilización de psicofármacos en atención primaria. Aten Primaria, 36:239-47. 
[WHO] World Health Organization Collaborating Centre for Drug Statistics and Methodology. 1995. Guidelines for ATC classification and DDD assignment. Oslo, Norway: WHO.

Woodward ND, Purdon SE, Meltzer HY, et al. 2007. A meta-analysis of cognitive change with haloperidol in clinical trials of atypical antipsychotics: dose effects and comparison to practice effects. Schizophr Res, 89:211-24.

Wu RR, Zhao JP, Liu ZN, et al. 2006. Effects of typical and atypical antipsychotics on glucose-insulin homeostasis and lipid metabolism in first-episode schizophrenia. Psychopharmacology (Berl), 186:572-8. 